\title{
Estrutura e ultra-estrutura de membranas biológicas de ovinos da raça Santa Inês (Ovis aries, L., 1758) a fresco e conservadas em glicerina
}

\author{
Roméria Rodrigues Barbosa \\ Leonardo Martins Leal * \\ Leandro Luis Martins \\ Sergio Pinter Garcia Filho \\ Andréa Cristina Scarpa Bosso \\ Márcia Rita Fernandes Machado \\ Universidade Estadual Paulista, CEP 14884-900, Jaboticabal - SP, Brasil \\ * Autor para correspondência \\ leonardo.vet@hotmail.com
}

Submetido em 28/11/2011

Aceito para publicação em 15/03/2012

\section{Resumo}

A utilização de implantes biológicos, de origem animal ou sintético, é recomendada na reconstrução de defeitos teciduais. Portanto, o objetivo deste estudo foi analisar a estrutura morfológica e ultraestrutural do peritônio parietal, pericárdio parietal, túnica vaginal e fáscia lata de 15 ovinos da raça Santa Inês, machos, adultos, provenientes da Estância Santa Bárbara do município de Poloni - SP. As membranas foram colhidas imediatamente após o abate dos animais, identificadas individualmente, e separadas em duas porções. A primeira foi armazenada em recipiente com solução fisiológica, denominando-as amostra a fresco. A outra porção foi conservada em glicerina a $98 \%$ por 15,30, 60 e 90 dias. Todas as amostras foram submetidas à técnica histológica usual, as amostras a fresco e as conservadas por 30 dias em glicerina receberam preparação especial para análise em microscópio eletrônico de varredura. Concluímos que as membranas, peritônio parietal, pericárdio parietal, túnica vaginal parietal e fáscia lata, de ovinos machos adultos da raça Santa Inês, a fresco ou conservadas, apresentaram um único tipo de tecido, o tecido conjuntivo denso não modelado. A glicerina a $98 \%$ utilizada como meio de conservação foi eficaz, na manutenção da integridade da estrutura tecidual das membranas.

Palavras-chave: Glicerina; Membranas biológicas; Ovinos; Peritônio

\section{Abstract}

Structure and ultrastructure of fresh and preserved biological membranes of Santa Inês sheep (Ovis aries, L., 1758). The use of biological implants, of animal or synthetic origin, is recommended for the reconstruction of tissue defects. Therefore, the objective of this study was to analyze the morphological structure and ultrastructure of the parietal peritoneum, parietal pericardium, tunica vaginalis and fascia lata of 15 Santa Inês sheep, which were adult males from Estância Santa Barbara, in the city of Poloni - SP. The membranes 
were collected immediately after the animals were slaughtered, individually identified and separated into two parts. The first part was stored in saline solution, and called the fresh sample. The other portion was stored in $98 \%$ glycerol for 15, 30, 60 and 90 days. All samples were subjected to standard histological techniques. Fresh samples and those preserved in glycerin for 30 days were also preparated and analyzed using scanning electron microscopy. We concluded that the fresh and preserved membranes, parietal peritoneum, parietal pericardium, tunica vaginalis and fascia lata, of the adult male Santa Inês sheep had a single type of tissue, which was unmodeled, dense connective tissue. The $98 \%$ glycerin used as a preservation medium was effective in maintaining the structural integrity of the tissue membranes.

Key words: Biological membranes; Glycerin; Peritoneum; Sheep

\section{Introdução}

Na reconstrução dos defeitos teciduais traumáticos, congênitos ou em decorrência de enfermidades, recomenda-se a utilização de implantes biológicos ou sintéticos, pois a aproximação por primeira intenção pode ocasionar tensão na linha de sutura e consequente deiscência da ferida cirúrgica (EURIDES et al., 1994).

Dentre os implantes biológicos, material de membranas obtidas de diferentes espécies animais são comumente utilizados, os quais, mediante processos de reparação, caracterizam-se por fornecer arcabouço, tanto para a orientação, quanto para o desenvolvimento de novos tecidos, restabelecendo a estrutura e a função do órgão afetado (BATISTA et al., 1996). Entre as membranas biológicas estudadas destacam-se o centro tendíneo, dura-máter, fáscia lata, pericárdio e peritônio, que são constituídas principalmente colágeno (ALVARENGA, 1992).

Quanto às espécies animais das quais se obtêm membranas biológicas para implantes, há pelo menos quatro décadas se tem investigado e utilizado membranas provenientes de cães, equinos, suínos e bovinos preservados em diferentes meios (PIGOSSI, 1964; 1967; INATOMI et al., 1980; DALECK et al., 1987; 1988; 1992; VÁMHIDY et al., 1990; ALVARENGA, 1992; REYES, 1993; BATISTA et al., 1996; SARTORI FILHO et al., 1997; COSTA NETO et al., 1999; MOTA et al., 2002; NOLASCO et al., 2003, STELMANN et al., 2010). As membranas biológicas têm como meio de conservação mais usual glicerina a $98 \%$, mantida em temperatura ambiente, que apresenta as seguintes vantagens: baixo custo, propriedade anti-séptica, rápida desidratação e fixação, manutenção da integridade celular e da textura original dos tecidos (ALVARENGA, 1992; WELLS et al., 2006).

Ensaios com membranas biológicas de bovinos têm apresentado resultados satisfatórios, como a duramáter utilizada na reparação da bainha do músculo reto do abdome de cães (INATOMI et al., 1980); peritônio tem sido utilizado nas seguintes situações: substituição de retalho diafragmático (DALECK et al., 1988), na reparação de hérnia perineal (DALECK et al., 1992), tenoplastia do tendão calcanear comum (COSTA NETO et al., 1999) e na esfincteroplastia do músculo esfíncter anal externo em cães (RODASKI et al., 2000).

O pericárdio bovino também foi utilizado na correção do parênquima pulmonar de cães após sua ressecção, na artroplastia acetábulo-femoral e como reforço da ráfia do peritônio no tratamento cirúrgico da eventração abdominal em equinos (VAUGHN et al., 1998; RODASKI et al., 2002; STELMANN et al., 2010).

A viabilidade da utilização do peritônio bovino como alternativa para o uso de tela cirúrgica implantada na parede abdominal foi testada em ratos, pois esta membrana biológica, pode ser preparada da mesma forma que o pericárdio bovino e, além disso, fornece maior área de tecido aproveitável por ser adaptável às diversas situações da prática cirúrgica (BASTOS et al., 2005).

Geralmente, os trabalhos que se referem às membranas biológicas avaliam a viabilidade e a sua aplicação em procedimentos cirúrgicos de várias regiões do organismo. Portanto há necessidade de estudos minuciosos sobre a morfologia dessas membranas e a exequibilidade de sua utilização. Sabendo-se que os ovinos constituem um grupo importante na 
experimentação, como modelo experimental para o homem, tanto no desenvolvimento de ensaios fisiológicos, quanto nos procedimentos cirúrgicos e ortopédicos, por apresentam algumas propriedades físicas semelhantes, entre as quais, como o tamanho de alguns órgãos (RAND, 2002), a pesquisa relativa às membranas biológicas nesses animais pode ser uma ferramenta útil nesse sentido.

Apesar de sua aptidão zootécnica, poucos são os relatos detalhados sobre a morfologia das membranas biológicas. Portanto o objetivo deste estudo foi analisar as estruturas e ultra-estruturas do pericárdio parietal, peritônio parietal, túnica vaginal parietal e fáscia lata de ovinos da raça Santa Inês, a fresco e conservadas em glicerina a $98 \%$, durante diferentes períodos.

\section{Material e Métodos}

\section{Animais}

Foram utilizados no presente estudo 15 ovinos da raça Santa Inês, adultos machos, fornecidos pela Estância Santa Bárbara do município de Poloni no Estado de São Paulo. O abate ocorreu no setor de caprinocultura da Faculdade de Ciência Agrárias e Veterinárias (FCAV/ UNESP), Campus de Jaboticabal.

\section{Colheita do material}

Após o abate, foram coletados o pericárdio parietal, o peritônio parietal, a túnica vaginal parietal e a fáscia lata. Após este procedimento, as amostras foram devidamente lavadas em água corrente para a retirada de resíduos.

O material foi dividido em duas porções. A primeira, denominada amostra a fresco, foi armazenada em solução fisiológica de $\mathrm{NaCl}$ a $0,9 \%$. A outra parte foi colocada em recipientes contendo glicerina a $98 \%$, conservada em temperatura ambiente; na proporção glicerina/membrana superior a 20:1.

\section{Processamento do material}

Após a colheita, as amostras a fresco, grupo controle, foram divididas em duas partes: uma delas foi encaminhada ao Setor de Técnicas Morfológicas do Laboratório de Anatomia, para o processamento e análise por microscopia de luz; a outra foi levada ao Laboratório de Microscopia Eletrônica para preparação e análise ultra-estrutural.

As amostras destinadas à conservação em glicerina a $98 \%$ foram divididas e processadas para a análise histológica aos 15, 30, 60 e 90 dias. A análise ultraestrutural foi realizada nas amostras conservadas em glicerina a $98 \%$ por 30 dias, tempo este considerado o mínimo para a conservação da membrana nesta substância, antes da sua utilização em cirurgias.

\section{Microscopia de Luz}

Os tecidos conservados em glicerina foram inicialmente reidratados em solução fisiológica de $\mathrm{NaCl}$ a $0,9 \%$, por 20 minutos, procedimento semelhante ao que são submetidos nos períodos pré e trans-operatório e, em seguida, processados mediante rotina histológica (TOLOSA et al., 2003).

Foram obtidos cortes de $5 \mu \mathrm{m}$, por micrótomo automático (Leica, RM 2155). O material foi corado hematoxilina e eosina (HE), de acordo com as técnicas descritas por Tolosa et al. (2003). Algumas preparações foram fotodocumentadas em microscópio de luz BX-50 (Olympus ${ }^{\circledR}$ ).

\section{Avaliação ultra-estrutural}

Seguindo metodologia estabelecida pelo Laboratório de Microscopia Eletrônica da FCAV/ UNESP, as amostras foram fixadas em solução de glutaraldeído a 2,5\% em tampão fosfato $(0,1 \mathrm{M}, \mathrm{pH} 7,4)$ por 48 horas, lavadas em tampão fosfato, tratadas com tetróxido de ósmio a 1\%, lavadas novamente em tampão fosfato, desidratadas em série crescente de etanóis (30\% a 100\%), durante 20 minutos cada etapa, secadas ao ponto crítico no aparelho EMS $850 \AA$, metalizadas com íons de ouro em um aparelho DESK II ${ }^{\circledR}$ (DETON VACUUM) examinadas e fotografadas ao microscópio eletrônico de varredura JEOL $®$ (JSM 5410), operando com feixe de elétrons de $15 \mathrm{keV}$. As observações relativas às diferentes amostras foram comparadas. 


\section{Resultados}

Observamos que, tanto o material a fresco como o conservado em glicerina, apresentaram a mesma constituição morfológica, embora estruturalmente, o material conservado em glicerina, apresentou um espaçamento entre as fibras de colágeno.

O pericárdico parietal a fresco é constituído de epitélio simples pavimentoso (mesotélio), repousando sobre camada de tecido conjuntivo frouxo, seguida por outra camada fibrocolágena compacta denominada de tecido conjuntivo denso não modelado, com fibras pouco acidófilas dispostas irregularmente, próximas entre si, e com núcleos de células (fibrócitos) acentuadamente basófilos; podemos observar também vasos sanguíneos muitas vezes circundados por tecido adiposo e a substância fundamental amorfa (Figura 1A).

Nas amostras de pericárdio parietal conservadas em glicerina a 98\%, nos dias 15, 30, 60 e 90, foi verificada uma desorganização tecidual, mais acentuada aos 15 dias (Figura 1B).

Com relação à amostra de peritônio parietal a fresco, observa-se disposição irregular de tecido fibrocolágeno chamado de tecido conjuntivo denso não modelado, revestido por epitélio simples pavimentoso (mesotélio), apresentando núcleo de célula (fibrobrócitos) basófilos, presença de vasos sanguíneos entremeados em tecido conjuntivo frouxo; substância fundamental amorfa (Figura 2A).

As amostras de peritônio parietal conservadas em glicerina 98\% nos dias 15, 30, 60 e 90 dias, apresentaram maior desorganização do tecido conjuntivo denso não modelado aos 15 dias, embora, aos 30 dias sua organização assemelha-se novamente às amostras a fresco (Figura 2B).

Quanto à túnica vaginal parietal, verificou-se nas amostras a fresco um epitélio simples pavimentoso (mesotélio) revestindo externamente o tecido conjuntivo denso não modelado, composto por fibras de colágeno acidófilas com disposição irregular, próximas entre si, apresentando núcleo basófilo de células do tecido conjuntivo. Observou-se também presença de vasos sanguíneos entremeados em fibras deste tecido conjuntivo (Figura 3A). Nas amostras de túnica vaginal, conservadas em glicerina a 98\%, nos dias 15, 30, 60 e 90 , verificou-se organização tecidual semelhante às preparações a fresco (Figura 3B).

No estudo microscópico da fáscia lata a fresco constatou-se, na parte externa dessa membrana, presença de epitélio simples pavimentoso (mesotélio) repousando sobre uma camada de tecido conjuntivo frouxo. Esta

FIGURA 1: Fotomicrografia de amostra de pericárdio parietal de ovinos da raça Santa Inês, HE, 200x. Em A, grupo controle (a fresco), o mesotélio (seta); tecido conjuntivo denso não modelado (CNM); fibras colágenas dispostas irregularmente (seta vazada); núcleo de fibrócitos $(\gg)$; vasos sanguíneos (v) entremeados em tecido conjuntivo frouxo (CF); substância fundamental amorfa (circulo). Em B, em glicerina 98\%, aos 15 dias, desorganização tecidual mais acentuada; presença de mesotélio (seta); tecido conjuntivo denso não modelado $(\mathrm{CNM})$; fibras colágenas dispostas irregularmente (seta vazada); núcleo de fibrócitos (\); vasos sanguíneos (v) entremeados em tecido adiposo (AD); substância amorfa (círculo).

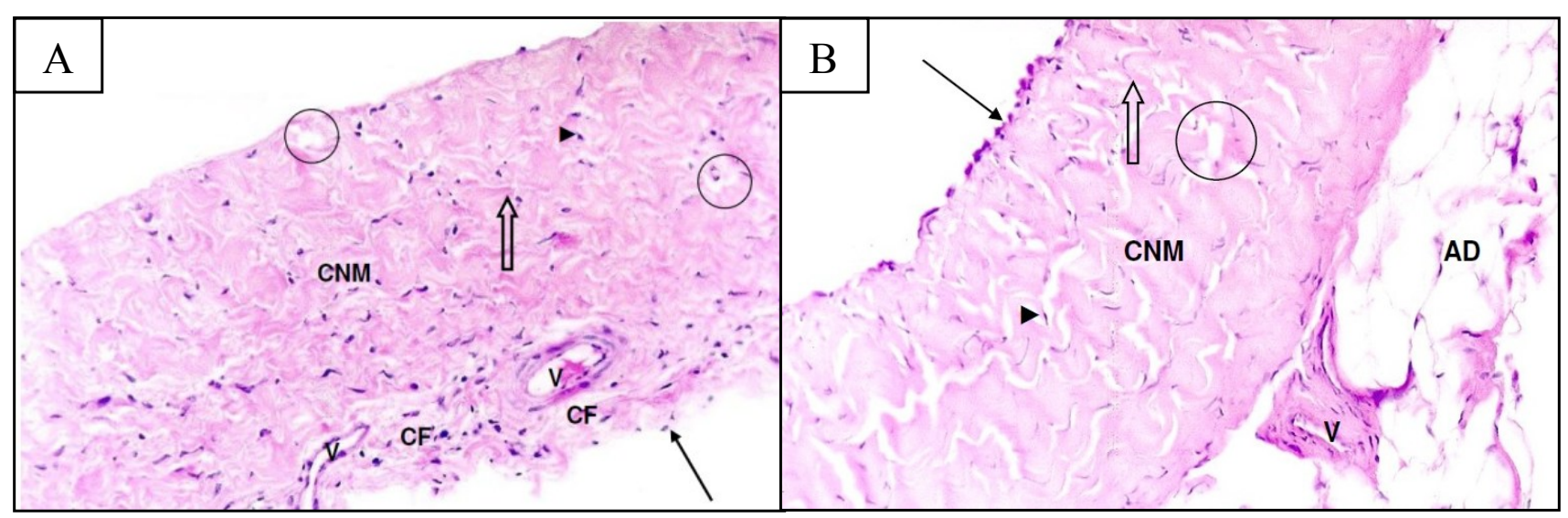


FIGURA 2: Fotomicrografia de amostra de peritônio parietal de ovinos da raça Santa Inês, HE, 200x. Em A, grupo controle (a fresco), mesotélio (seta); tecido conjuntivo denso não modelado (CNM); fibras colágenas dispostas irregularmente (seta vazada); núcleo basófilos de fibrócitos ( $)$; vasos sanguíneos (v) entremeados em tecido conjuntivo frouxo evidente (CF); substância fundamental amorfa (circulo). Em B, glicerina 98\%, aos 15 dias, desorganização tecidual mais acentuada, presença de mesotélio (seta); tecido conjuntivo denso não modelado (CNM); fibras colágenas dispostas irregularmente (seta vazada); núcleos basófilos de fibrobrócitos ( $\$ ); vasos sanguíneos (v) entremeados no tecido conjuntivo frouxo (CF); substância fundamental amorfa (círculo).

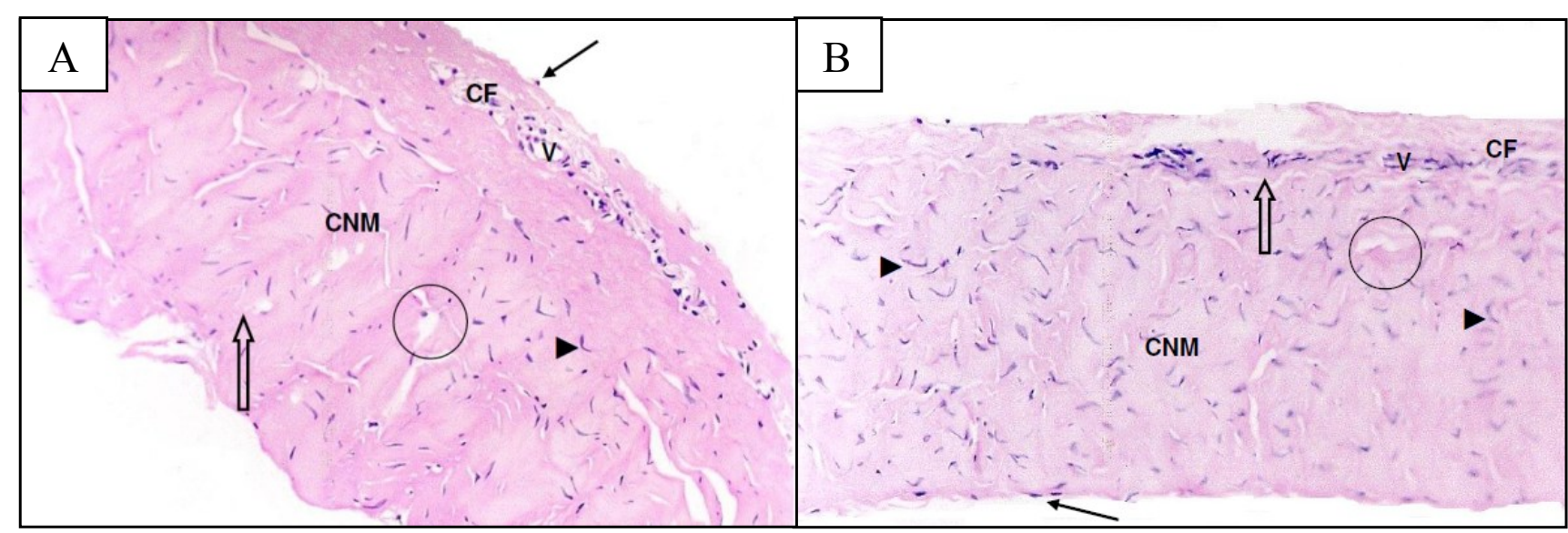

FIGURA 3: Fotomicrografia de amostra da túnica vaginal parietal de ovinos da raça Santa Inês, HE, 200x. Em A, grupo controle (a fresco), mesotélio (seta); tecido conjuntivo denso não modelado (CNM); fibras colágenas acidófilas dispostas irregularmente (seta vazada); núcleos basófilos de fibrobrócitos ( $)$; vasos sanguíneos (v) entremeados em fibras de colágeno deste tecido conjuntivo; substância fundamental amorfa (círculo). Em B, em glicerina 98\%, aos 15 dias, organização tecidual semelhante às preparações a fresco; presença de mesotélio (seta); tecido conjuntivo denso não modelado (CNM); vasos sanguíneos (v) entremeados nas fibras de colágeno deste tecido, com fibras dispostas irregularmente (seta vazada); núcleo basófilos de fibrobrócitos ( ) substância fundamental amorfa (círculo).

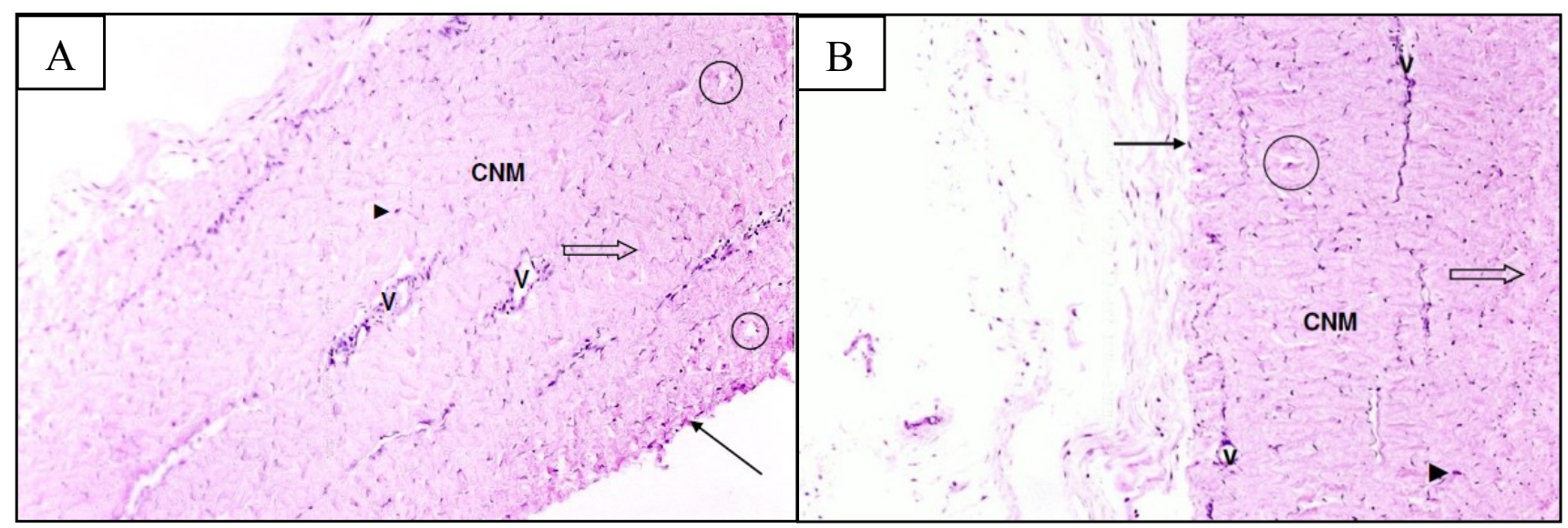


camada externa é continua ao tecido conjuntivo denso não modelado, composto de fibras acidófilas dispostas em todas as direções, núcleos de células do tecido conjuntivo, basófilos e vasos sanguíneos (Figura 4A).

Nas amostras de fáscia lata, conservadas em glicerina a 98\%, nos dias 15, 30, 60 e 90, foi observada organização tecidual semelhante das amostras a fresco (Figura 4B).
Mediante a análise pela microscopia eletrônica de varredura verificou-se a integridade da organização tecidual das membranas a fresco e em glicerina a $98 \%$ no $30^{\circ}$ dia; não foram observadas intensa defibrilação, apenas um leve desarranjo (Figuras 5A, 5B, 5C, 5D, $5 \mathrm{E}, 5 \mathrm{~F}, 5 \mathrm{G}, 5 \mathrm{H})$.

FIGURA 4: Fotomicrografia de amostra da fáscia lata de ovinos da raça Santa Inês, HE, 200x. Em A, grupo controle (a fresco), o mesotélio (seta); tecido conjuntivo frouxo (CF) envolvendo as grossas fibras de colágeno do tecido conjuntivo denso não modelado (CNM); fibras colágenas acidófilas dispostas irregularmente (seta vazada); núcleos basófilos de fibrócitos ( ). Em B, em glicerina $98 \%$, aos 15 dias, organização tecidual semelhante às preparações a fresco; mesotélio (seta); tecido conjuntivo frouxo (CF) envolvendo as grossas fibras colágenas do tecido conjuntivo denso não modelado (CNM); fibras dispostas irregularmente (seta vazada); núcleos basófilos de fibrobrócitos ( ); notar a presença de vasos sanguíneos (v) entremeados no tecido adiposo $(\mathrm{AD})$.

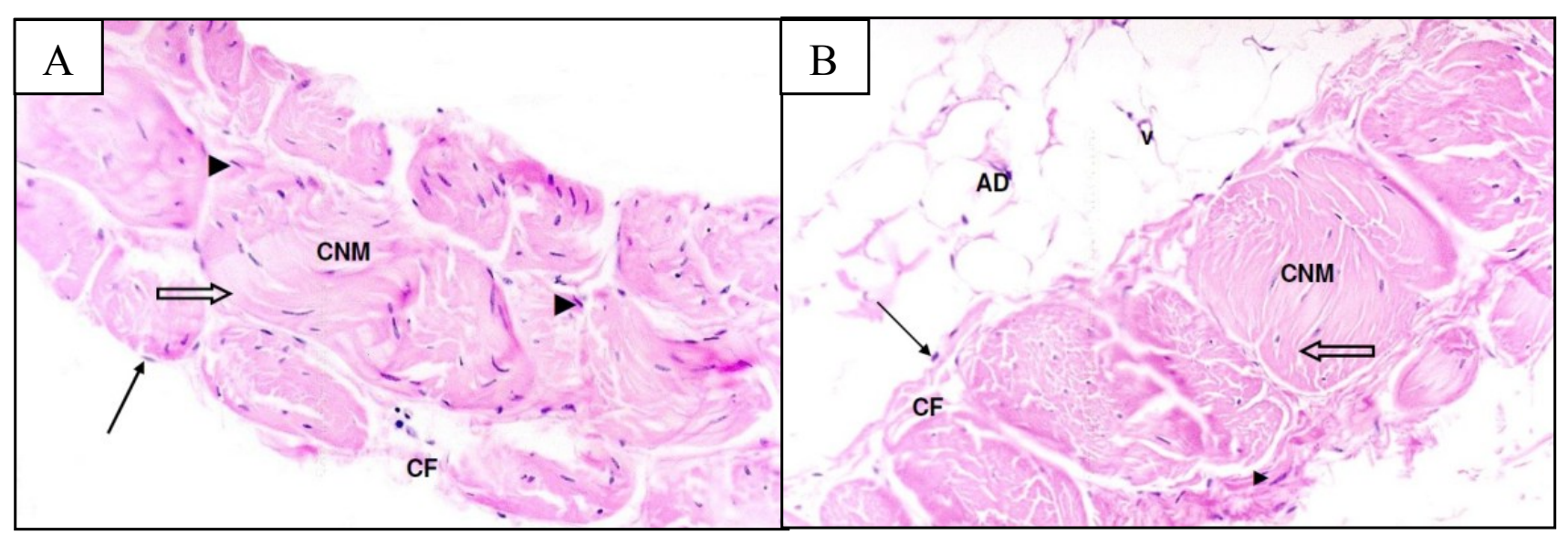


FIGURA 5: Eletromicrografia de varredura de membranas de ovinos da raça Santa Inês, 1000x. Em A e B, pericárdio parietal a fresco e em glicerina 98\% respectivamente, fibras colágenas dispostas irregularmente (seta). Em C e D, peritônio parietal a fresco e em glicerina 98\% respectivamente, o mesotélio (M). Em E, a fresco, observa em as células achatadas do mesotélio (M) e fibras colágenas disposta irregularmente (seta), 100x. Em F, túnica vaginal parietal em glicerina 98\%, fibras colágenas dispostas irregularmente (seta). Em G e H, fáscia lata a fresco e em glicerina 98\% respectivamente, grossas fibras colágenas dispostas irregularmente.

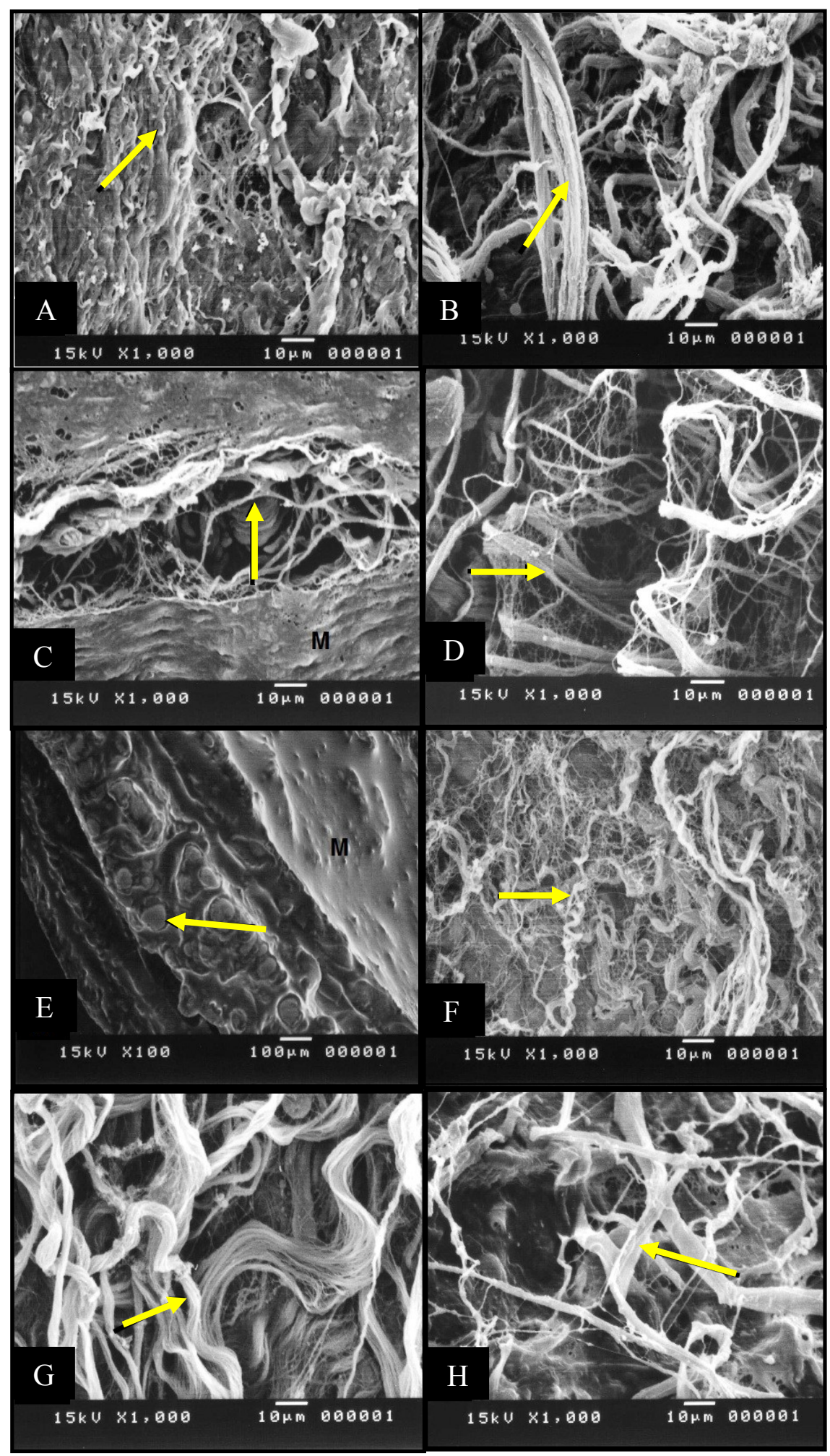




\section{Discussão}

Quanto às observações microscópicas sobre as membranas de ovinos da raça Santa Inês, as estruturas assemelham-se às descrições da literatura de que as membranas serosas são formadas por uma camada de mesotélio e por tecido conjuntivo associado (NICKEL et al., 1985; BANKS, 1992; STEVENS; LOWE, 1992; GEORGE et al., 1998; DI DIO, 1999; GARTNER; HIATT, 1999; HIB, 2003; DYCE et al., 2004; JUNQUEIRA; CARNEIRO, 2004).

Neste trabalho não foi possível avaliar se esses envoltórios serosos, com função de revestimento de órgãos, contribuem para o processo de reparação tecidual, uma vez que esta propriedade, segundo Banks (1992), está relacionada à deposição de fibrina no tecido conjuntivo submesotelial e subseroso, promovendo a diminuição do extravasamento no processo de reparação, vedando a ferida e posterior atividade dos fibroblastos, quando há uma injuria tecidual.

Quanto ao tecido encontrado nas membranas, tanto a fresco, quanto conservadas em glicerina, durante períodos variados, ou seja, tecido conjuntivo denso não modelado, este se apresenta da mesma forma que descrevem Banks (1992), Stevens e Lowe (1992), George et al. (1998), Gartner e Hiatt (1999), Hib (2003), Dyce et al. (2004) e Junqueira e Carneiro (2004), que relatam a presença de fibras colágenas agrupadas em feixes que se entrelaçam e seguem nas mais variadas direções, formando uma intricada rede tridimensional em permeio a uma escassa substância fundamental amorfa. Estes achados foram confirmados neste trabalho pelas observações das amostras por microscopia eletrônica de varredura.

Observamos a presença de tecido conjuntivo frouxo, bem evidenciado, especialmente abaixo do mesotélio e circundando os vasos sanguíneos e as fibras do tecido conjuntivo denso não modelado; esta ocorrência deve-se provavelmente, ao fato de que o tecido conjuntivo frouxo é um tecido de preenchimento que suporta estruturas sujeitas a pequenos atritos e pressões.

As membranas avaliadas apresentaram todos os elementos estruturais típicos do tecido conjuntivo propriamente dito, não havendo, entretanto, nenhuma predominância de qualquer de seus componentes como já relatado por Banks (1992), Stevens e Lowe (1992), George et al. (1998), Gartner e Hiatt (1999), Hib (2003), Dyce et al. (2004) e Junqueira e Carneiro (2004).

Como observado por Alvarenga (1992), a glicerina utilizada como meio de conservação das membranas pôde ser mantida em temperatura ambiente, o que facilitou a sua utilização e dispensou o uso de meios de conservação de custo elevado.

Neste estudo, a glicerina, mostrou-se eficiente na manutenção da integridade do material analisado, assim como constatado por Prista et al. (1990), Alvarenga (1992) e Mota et al. (2002). Por apresentar esta qualidade Daleck et al. (1992), Costa Neto et al. (1999), Oliveira et al. (1999), Brun et al. (2000), Contesini et al. (2001) e Raiser et al. (2001) afirmam que a glicerina a $98 \%$ é um dos meios conservantes mais amplamente utilizados, tanto em casos clínicos, quanto em estudos experimentais.

Mediante as indicações de Alvarenga (1992) e de Smith et al. (1996) que preconizam a variação do tempo de reidratação de membranas de acordo com a forma, espessura e tamanho das estruturas analisadas e as observações de Sartori Filho et al. (1997) que recomendam um período de pelo menos 15 minutos para a conservação de tecidos em glicerina, para as membranas de ovinos da raça Santa Inês, considerando as dimensões das amostras, o tempo de reidratação foi de 20 minutos.

Quanto à integridade morfológica e estrutural dos elementos constituintes das amostras do material a fresco e das conservadas em glicerina a $98 \%$, verificou-se neste experimento resultados semelhantes aos relatados por Daleck et al. (1988), que observaram no peritônio bovino conservado em glicerina a $98 \%$ por 60 dias aspectos semelhantes ao mesmo material a fresco. Esses dados estão de acordo com os achados de Daleck et al. (1987), que não observaram alterações no aspecto das células mesoteliais e das fibras conjuntivas de peritônio autólogo ou homólogo conservado em glicerina, durante 30, 90 ou 240 dias.

Com relação ao espaçamento entre as fibras de colágeno, esta característica foi observada nas 
preparações em glicerina a 98\%, por 15 dias, e não foram observadas nas amostras provenientes do material a fresco. Para Pigossi et al. (1971) e Wells et al. (2006) o fato da glicerina apresentar acentuada hidrofilia, devido à sua polaridade, é capaz de atrair átomos de hidrogênio das moléculas vizinhas, promovendo uma reação química, e preservando a arquitetura tecidual.

Entretanto, tanto a glicerina quanto a água, promoveram a condensação do volume, causando uma desidratação, propriedade fundamental para explicar tanto a ocorrência de delaminação, ou seja, deslocamento das camadas de colágeno e retração dos núcleos.

As alterações observadas nas preparações histológicas analisadas estavam intrinsecamente relacionadas às propriedades da glicerina, que não interferiu na integridade tecidual, uma vez que tanto as membranas a fresco, quanto às conservadas em glicerina a $98 \%$ por períodos entre 15 a 90 dias apresentaram, o mesmo arranjo estrutural, portanto, a glicerina a $98 \%$ é eficiente na conservação de membranas biológicas como já evidenciado por Pigossi, (1964; 1967), Pigossi et al. (1971), Daleck et al. (1987; 1988; 1992), Alvarenga, (1992), Costa neto et al. (1999), Oliveira et al. (1999), Brun et al., (2000), Contesini et al. (2001), Raiser et al. (2001), Mota et al. (2002), Wells et al. (2006) e Stelmann (2010).

Neste estudo observou-se que o pericárdio parietal a fresco e conservado em glicerina é estruturalmente semelhante ao descrito por Stevens e Lowe (1992) e Ross (1999), sendo formado por uma camada de serosa composta por tecido conjuntivo frouxo e epitélio pavimentoso simples (mesotélio), além da camada de tecido conjuntivo denso não modelado, com largas e grosseiras faixas de colágeno, assim o pericárdio parietal dá forma a um saco forte para a proteção do coração (ROSS, 1999).

Microscopicamente, o peritônio se apresenta formando uma camada superficial de mesotélio seguida por uma camada de tecido conjuntivo frouxo com fibras elásticas e colágenas (DYCE et al., 2004; JUNQUEIRA; CARNEIRO, 2004). Esta organização é observada no peritônio dos ovinos da raça Santa Inês formado por tecido conjuntivo denso não modelado, cujas fibras estão dispostas irregularmente, próximas entre si, as extremidades desta serosa verifica-se a presença de mesotélio apoiado sobre delgada camada de tecido conjuntivo frouxo.

O peritônio de ovino conservado em glicerina, não sofreu alterações quanto ao arranjo estrutural do tecido. Assim como relatado por Daleck et al. (1987; 1988; 1992).

A túnica vaginal de ovinos da raça Santa Inês, estrutura derivada do peritônio (JUNQUEIRA; CARNEIRO, 2004), possui as mesmas características desta membrana, ou seja, mesotélio seguido pelo tecido conjuntivo denso não modelado; estes achados se assemelham aos de Noronha et al. (2001) no jumento e de Carvalhal et al. (2000) em ovinos da raça Corriedale.

A fáscia lata dos ovinos da raça Santa Inês é constituída por tecido conjuntivo denso não modelado, circundado por tecido conjuntivo frouxo; assemelham-se também aos achados de Bacon et al. (1984) e Silva et al. (2000), que ao avaliarem microscopicamente a fáscia lata de cães, relataram que sua estrutura dispõe-se em feixes, com aspectos ondulados, envolvidos por tecido conjuntivo frouxo.

Mediante os resultados analisados pode-se concluir que as membranas, pericárdio parietal, peritônio parietal, túnica vaginal parietal e fáscia lata, a fresco ou conservadas, de ovinos da raça Santa Inês, apresentaram um único tipo de tecido, o tecido conjuntivo denso não modelado. A glicerina a $98 \%$ utilizada como meio de conservação das membranas permitiu a preservação das estruturas de forma semelhante às amostras a fresco mesmo nas membranas armazenadas por 90 dias. Assim, concluímos que a glicerina a $98 \%$ foi eficiente na manutenção estrutural e tecidual das membranas.

\section{Referências}

ALVARENGA, J. Possibilidades e limitações da utilização de membranas biológicas preservadas em cirurgia. In: DALECK, C. R.; BAPTISTA, L. C.; MUKAI, L. S. Tópicos em cirurgia de cães e gatos. Jaboticabal: FUNEPUNESP, 1992. p. 33-42.

BACON, M. J. P.; PICHELER, M. E.; LYND, F. T. Histopathological examintion of two cranial cruciate ligaments reconstructions. Journal of the American Veterinary Medical Association, Chicago, v. 20, n. 1, p. 65-68, 1984. 
BANKS, W. J. Organização dos órgãos. In: BANKS, W. J. Histologia veterinária aplicada. 2. ed. São Paulo: Manole, 1992. p. 282-288.

BASTOS, E. L. S.; FAGUNDES, D. J.; TAHA, M. O.; NOVO, N. F.; SILVADO, R. A. B. Peritônio bovino conservado na correção de hérnia ventral em ratos: uma alternativa para tela cirúrgica biológica. Revista do Colégio Brasileiro de Cirurgia, Rio de Janeiro, v. 32, n. 5, p. 256-260, 2005.

BATISTA, L. C.; DALECK, C. R.; SHIMANO, A. C.; ALESSI, A. C.; ABRAHÃO, M. S. Estudo comparativo da resistência à tração do peritônio (bovino, equino, suíno e canino) a fresco e conservado em glicerina. Brazilian Journal of Veterinary Research and Animal Science, São Paulo, v. 33, p. 305-312, 1996.

BRUN, M. V.; PIGATTO, J.A. T.; DRIEMEIER, D.; OLIVEIRA, L. O.; BECK, C. A. C.; AGUIAR, E. V.; DIAS FREIRE, C.; GAIGA, L. H. Traqueoplastia em cães com pericárdio eqüino conservado em glicerina por um período de 11 anos. Revista Brasileira de Ciência Veterinária, Niterói, v. 7, p. 58, 2000.

CARVALHAL, R.; BORELLI, V.; MIGLINO, M. A. Estudo morfológico do funículo espermático em ovinos da raça Corriedale (Ovis aires, L. 1758). Brazilian Journal of Veterinary Research and Animal Science, São Paulo, v. 37, n. 5, 2000.

CONTESINI, E. A.; SALLES, M. S.; PIGATTO, J. A. T.; PIPPI, N. L.; RAISER, A. G. Reparação traqueal em cães: transplante autógeno vs implante homógeno conservado em glicerina a $98 \%$ de cartilagem da pina. Ciência Rural, Santa Maria, v. 31, n. 4, p. 633-637, 2001.

COSTA NETO, J. M.; DALECK, C. R.; ALESSI, A. C.; BRACCIALLI, C. S. Tenoplastia experimental do calcâneo em cães com peritônio bovino conservado em glicerina. Ciência Rural, Santa Maria, v. 29, n. 4, p. 697-703, 1999.

DALECK, C. R.; DALECK, C. L. M.; ALESSI, A. C.; PADILHA FILHO, J. G.; COSTA NETO, J. M. Substituição de um retalho diafragmático de cão por peritônio de bovino conservado em glicerina: estudo experimental. Ars Veterinária, Jaboticabal, v. 4, n. 1, p. 53-61, 1988.

DALECK, C. R.; DALECK, C. L. M.; GANDOLFI, W.; ALESSI, A. C. Esofagoplastia cervical no cão com peritônio autólogo ou homólogo conservado em glicerina - "estudo experimental". Ars Veterinária, Jaboticabal, v. 3, n. 2, p. 195-202, 1987.

DALECK, C. R.; DALECK, C. L. M.; PADILHA FILHO, J. G.; COSTA NETO, J.M. Reparação de hérnia perineal em cães com peritônio de bovino conservado em glicerina. Ciência Rural, Santa Maria, v. 22, n. 2, p. 179-183, 1992.

DI DIO, L. J. A. Tratado de anatomia aplicada. v. 2. São Paulo: Póluss Editorial, 1999. 948 p.

DYCE, K. M.; SACK, W. O.; WENSING, C. J. G. Tratado de anatomia veterinária. 3. ed. Rio de Janeiro: Elsevier, 2004. 813 p. EURIDES, D.; NIGRO, A. J. T.; GOLDENBERG, S. Reparo de defeito provocado no diafragma de cães com segmento livre peritônio-muscular. Estudo experimental. Acta Cirúrgica Brasileira, São Paulo, v. 9, p. 131-135, 1994.

GARTNER, L. P.; HIATT, J.L. Tratado de histologia. 1 ed. Rio de Janeiro: Guanabara Koogan, 1999. 426 p.

GEORGE, L. L.; ALVES, C. E. R.; CASTRO, R. R. L. Histologia comparada. 2 ed. São Paulo: Roca, 1998. 286 p.
HIB, J. Histologia de Di Fiore. Rio de Janeiro: Guanabara Koogan, 2003. 513 p.

INATOMI, L. S.; PRANTONI, G. A.; ARAÚJO, F. C.; RAISER, A. G.; PEREIRA, S. N.; CARDOSO, G.; BARROS, S. S.; SANTOS, M. N. Implante de dura-máter heteróloga em cães. Revista do Centro de Ciências Rurais, Santa Maria, v. 10, n. 3, p. 291-297, 1980.

JUNQUEIRA, L. C.; CARNEIRO, J. Histologia básica. 10 ed. Rio de Janeiro: Guanabara Koogan, 2004. 487 p.

MOTA, F. C. D.; EURIDES, D.; BELLETTI, M. E.; FREITAS, P. M. C.; MASTRANTONIO, E. C.; SHIMIZU, B. J.; CARDOSO, J. R.; MARTINS, A. K. Análise ultra-estrutural da túnica muscular do intestino delgado de cães preservado em diferentes meios. Brazilian Journal of Veterinary Research and Animal Science, São Paulo, v. 39, n. 1/6, p. 13-17, 2002.

NICKEL, R.; SCHUMMER, A.; SEIFERLE, E.; WILKENS, H.; WILLE, K. H.; FREWEIN, J. The anatomy of domestic animals - The locomotor system of the domestic mammals. v. 1. Berlin: Verlag Paul Parey, 1985. 395 p.

NOLASCO, R. M.; BELETTI, M. E.; EURIDES, D.; SILVA, F. O. C. E.; COELHO, H. E.; DALECK, C. R.; SILVA, L. A. F. Avaliação histológica e ultraestrutural de tendões de bovinos preservados em diferentes meios. Ars Veterinária, Jaboticabal, v. 19, n. 3, p. 210 $215,2003$.

NORONHA, P. B.; NETO, J. P.; BORELLI, V. Aspectos morfológicos do funículo espermático de jumentos (Equus asinus, L.1758) da raça Pêga. Brazilian Journal of Veterinary Research and Animal Science, São Paulo, v. 38, n. 5, p. 13-17, 2001.

OLIVEIRA, L. O.; PIPPI, N. L.; GRAÇA, D. L.; FARIA, R. X.; GUIMARÃES, L. D.; GUEDES, A. G. P.; PELLEGRINNI, L. C.; FERNANDES, R. R.; ALVES, A. S. Implante homógeno de bexiga conservada em glicerina a $98 \%$ para reparo da bexiga de cães. Arquivos da Faculdade de Veterinária da UFRGS, Porto Alegre, v. 27, n. 1, p. 90-102, 1999.

PIGOSSI, N. Implantação de dura-máter homógena conservada em glicerina - estudo experimental em cães. 1964. 41 f. Tese (Doutorado em Medicina) - Universidade de São Paulo, São Paulo. 1964.

PIGOSSI, N. A glicerina na conservação de dura-máter: estudo experimental. 1967. 83 f. Tese (Livre Docência) - Universidade de São Paulo, São Paulo. 1967.

PIGOSSI, N.; RAIA, A.; LEX, A.; GAMA, A. H.; SIMONSEN, O.; HADDAD, J.; STOLF, N.; ZERBINI, E. J.; MINITI, A.; TENUTO, R. Estudo experimental e clínico sobre o emprego, como implante, da dura-máter homógena conservada em glicerina à temperatura ambiente. Revista da Associação Médica Brasileira, São Paulo, v. 17, n. 8 , p. 263-278, 1971.

PRISTA, L. N.; ALVES, A. C.; MORGADO, R. M. R. Técnica farmacêutica e farmácia galênica. 3 ed. v. 2. Lisboa: Fundação Calouste, 1990. 508 p.

RAISER, A. G.; GRAÇA, D. L.; PIPPI, N. L.; ZINN, L. L.; SILVEIRA, D. S.; BORDIN, A. I.; BAIOTTO, G. C.; RIOS, M. V.; SILVEIRA, A. F. Homoimplante ortotópico de tendão calcâneo em cães. Conservação, assepsia e implantação. Ciência Rural, Santa Maria, v. 31, n. 1, p. 89-94, 2001.

RAND, M. S. Farm animals as models for biomedical research. 2002. Disponível em: <http://www.ahsc.arizona.edu/uac/notes/ 
classes/farmmodels/farmanim_as_biomodels02.html/>. Acesso em: 27 maio 2005.

REYES, E. E. F. Testes físicos comparativos de membranas biológicas preservadas em glicerina, congeladas e a fresco. 1993. 85 f. Dissertação (Mestrado em Cirurgia Veterinária) Universidade de São Paulo, São Paulo. 1993.

RODASKI, S.; CUNHA, O.; NARDI, A. B.; RIOS, A.; COMAR, F. A.; CASTRO, J. H. T. Artroplastia acetábulo-femoral em cães com pericárdio bovino conservado. Archives of Veterinary Science, Curitiba, v. 7, n. 2, p. 179-187, 2002.

RODASKI, S.; GUÉRIOS, S. D.; KOPPE, A. B.; SINCERO, P.C.;TRANQUILIN, M.V.; PERRONI, M. A.; NARDI, A. B Mioplastia experimental do esfíncter anal externo com fascia lata autóloga, em cães. Archives of Veterinary Science, v. 5, n. 1, p. 49-54, 2000.

ROSS, J. Composition of the heart. 1999. Disponível em <www. jdaross.cwc.net/heart4.htm>. Acesso em: 24 outubro 2006.

SARTORI FILHO, F.; GANDOLFI, W.; BANDARRA, E. P. Emprego da membrana biológica (centro frênico) na reparação das lesões tendíneas em coelhos. Veterinária e Zootecnia, São Paulo, v. 9, n. 1, p. 69-77, 1997.

SILVA, A. M.; CARLO, R. J. D.; FONSECA, C. C.; GALVÃO, S. R.; FILHO, A. M. Aspectos macro e microscópicos da fáscia lata utilizada como substituto autológo do ligamento cruzado cranial. Ciência Rural, Santa Maria, v. 30, n. 2, p. 275-280, 2000.

SMITH, C. W.; YOUNG, I. S.; KEARNEY, J. N. Mechanical properties of tendons with sterilization and preservation. Journal of Biomechanical Engineering, New York, v. 118, n. 1, p. 56-61, 1996.
STEVENS, A.; LOWE, J. S. Histology. London: Gowen Medical Publishing, 1992. $358 \mathrm{p}$.

STELMANN, U. J. P.; SILVA, A. A.; SOUZA, B. G.; HESS, T. M.; AGUIAR, G. C.; SANTOS, A. E. Utilização de pericárdio bovino como reforço da ráfia do peritônio no tratamento cirúrgico de eventração em eqüino: relato de caso. Revista Científica Eletrônica de Medicina Veterinária, Garça, v. 8, n. 14, 2010.

TOLOSA, E.M.C.; RODRIGUES, C.J.; BEHMER, O.A.; FREITAS NETO, A.G. Manual de técnicas para histologia normal e patológica. 2. ed. São Paulo: Manole, 2003. 37 p.

VAUGHN, C. C.; VAUGHN, P. L.; VAUGHN III, C. C.; SAWYER, P.; MANNING, M.; ANDERSON, D.; ROSEMAN, L.; HERBST, T. J. Tissue response to biomaterials used for staple-line reinforcement in lung resection: a comparison between expanded polytetrafluoroethylene and bovine pericardium. European Journal Cardio-thoracic Surgery, Amsterdam, v. 13, n. 1, p. 259265, 1998.

VÁMHIDY, L.; STRAUCH, B.; BIRÓ, V. Preserved tendon grafts in reconstructive hand surgery: a review. Acta Chirurgica Hungarica, Budapest, v. 31, n. 3, p. 209-215, 1990.

WELLS, P. B.; YEH, A. T.; HUMPHREY, J. D. Influence of glycerol on the mechanical reversibility and thermal damage susceptibility of collagenous tissues. IEEE Transactions on Biomedical Engineering, New York, v. 53, n. 4, p. 747-753, 2006. 